\title{
Induction Machine Fault Identification Using Particle Swarm Algorithms
}

\author{
S. A. Ethny, P. P Acarnley, B. Zahawi, Senior Member, IEEE, and D. Giaouris, Member, IEEE
}

\begin{abstract}
The principles of a new technique using particle swarm algorithms for condition monitoring of the stator and rotor circuits of an induction machine is described in this paper. Using terminal voltage and current data, the stochastic optimization technique is able to indicate the presence of a fault and provide information about the location and nature of the fault. The technique is demonstrated using experimental data from a laboratory machine with both stator and rotor winding faults.
\end{abstract}

Index Terms--Condition monitoring, induction machine, stochastic optimization, swarm algorithms.

\section{INTRODUCTION}

$\mathrm{C}$ induction machine condition embedded sensors to measure, for example, temperature or vibration and help detect a developing fault. There has also been considerable interest in detecting winding and other machine faults by current signature analysis of stator current waveforms [2]. This involves frequency-domain analysis of data gathered under steady-state operating condition and may involve the calculation of quantities such as input power [3] or machine negative sequence components [4]. More recently, other fault detection methods using data acquired during speed transients [5] and estimation of machine parameters [6] have also been suggested.

This paper describes a new technique for machine condition monitoring and fault identification from terminal and rotor position data obtained during transient operation. In this method, a stochastic search is carried out using particle swarm algorithms to estimate values of winding resistance which give the best possible match between the performance of the faulty experimental machine and its mathematical model, thus identifying both the location and nature of the winding fault.

\section{SCHEMATIC DESCRIPTION OF THE NEW METHOD}

Fig. 1 shows a schematic diagram of the new fault identification technique. Terminal voltage and rotor position data from a laboratory induction machine is used as the input to a transient $\mathrm{ABCabc}$ to calculate the three stator currents. These calculated currents are then compared to the actual measured currents to produce a set of current errors that are integrated then summed to give an overall calculation error.

When the machine is in its healthy state, its effective parameters correspond to the model parameters and the calculation error is small. If a fault occurs in the machine's windings its electrical parameters are of course modified and when the measured stator currents are compared to the calculated currents there will be a large calculation error giving a fast indication that a fault of some type is present. Fault identification is carried out by adjusting the model parameters, using a stochastic search method, such as particle swarm algorithms, to minimize the error. The new set of model parameters then defines the nature and location of the fault, for example, an increased value of resistance for stator winding b, indicates a developing open-circuit condition in that circuit, and so on.

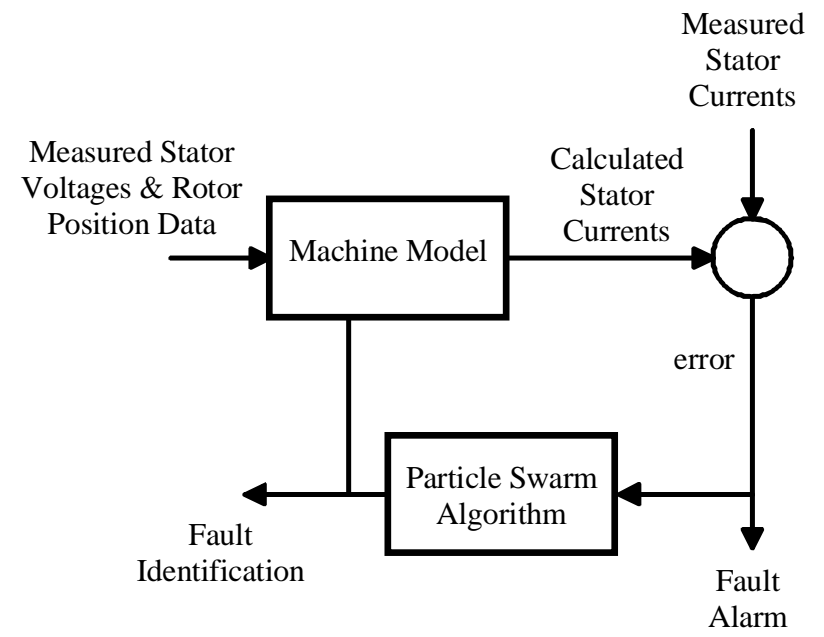

Fig. 1. Schematic representation of the fault identification technique using particle swarm algorithms.

A. Ethny, B. Zahawi and D. Giaouris are with the School of Electrocal, Electronic \& Computer Engineering, Newcastle University, Newcastle upon Tyne NE1 7RU, UK (email: bashar.zahawi@ncl.ac.uk).

P. P. Acarnley is with Research Engineering Education Services, Stonehaven, Scotland, UK (email: paul.acarnley@reseeds.com).

0-7803-9771-1/06/\$20.00 @2006 IEEE.

\section{A. Particle Swarm Optimization}

Particle Swarm Algorithms (PSA) is an evolutionary computation technique [7] inspired by social behavior of bird 
flocking. Like other evolutionary optimization techniques such as Genetic Algorithms, it is based on a population of randomly generated potential solutions that are dynamically adjusted in an iterative process in search for an optimum solution. Unlike GA techniques however, the particle swarm algorithm is not based on the idea of the survival of the fittest. Members of the population with lower fitness functions do survive during the optimization process and can potentially visit any point in the search space.

Each bird or member of the population in a PSA $\mathbf{X}_{\mathrm{i}}$ is treated as a point in the $\mathrm{N}$-dimensional space representing the optimization problem, so that:

$$
\mathbf{X}_{\mathrm{i}}=\left(x_{i 1}, x_{\mathrm{i}}, \ldots, x_{i \mathrm{~N}}\right) \text { for } i=1,2, \ldots, \mathrm{M}
$$

where $\mathrm{N}$ is the number of variables and $\mathrm{M}$ is the number of particles that form the population.

The position of each particle within the search space is a potential result that can be evaluated in accordance with a given performance function to assess the fitness value of that member of the population. In addition to its position within the search space, each particle is free to fly with a velocity $\mathbf{V} i$ that is continuously adjusted in accordance with the flying history (i.e. position and speed) of the particle itself and of other members of the population.

$$
\mathbf{V}_{\mathrm{i}}=\left(v_{i 1}, v_{\mathrm{i} 2}, \ldots, v_{i \mathrm{~N}}\right) \text { for } i=1,2, \ldots, \mathrm{M}
$$

The dynamic equations for the particle swarm algorithm are given by:

$$
\begin{aligned}
& v_{i n}^{k+1}=w v_{i n}^{k}+a_{1} b_{1}^{k}\left(p_{i n}^{k}-x_{i n}^{k}\right)+a_{2} b_{2}^{k}\left(p_{g n}^{k}-x_{g n}^{k}\right) \\
& x_{i n}^{k+1}=x_{i n}^{k}+v_{i n}^{k+1}
\end{aligned}
$$

where $n=(1,2, \ldots, \mathrm{N}), \quad i=(1,2, \ldots, \mathrm{M}), a_{1}$ and $a_{2}$ are positive constants used to fine tune the operation and convergence of the algorithm, $b_{1}$ and $b_{2}$ are random numbers between 0 and $1, p_{g n}$ is the position of the best particle in the flock, i.e. the bird with the best position and $w$ is a weighting function that determined the extent to which previous velocities can influence the current velocity of the particle. A large value of $\mathrm{w}$ assists the exploration of new areas by the flock, whereas a small value will restrict or narrow the search area for fine tuning purposes.

To apply this concept to condition monitoring of an induction machine or for machine parameter identification [8], each individual $\mathbf{X}_{\mathrm{i}}$ in the bird population represents one set of values of the machine winding resistances $\left(R_{\mathrm{sa}}, R_{\mathrm{sb}}, R_{\mathrm{sc}}, R_{\mathrm{ra}}\right.$, $R_{\mathrm{rb}}$ and $R_{\mathrm{rc}}$ ) where the resistance values must lie within a predefined search space. In this paper the resistance values are allowed to vary from $0.1 x$ to $5 x$ their nominal values.

\section{B. Mathematical Model of the Motor}

Assuming that the machine has a smooth air-gap, the threephase machine equations can be written in the natural ABCabc reference frame (Equation 5), where $v_{\mathrm{A}}, v_{\mathrm{B}}, v_{\mathrm{C}}, i_{\mathrm{A}}, \mathrm{i}_{\mathrm{B}}$, $\mathrm{i}_{\mathrm{C}}$ are stator winding voltages and currents, $v_{\mathrm{a}}, v_{\mathrm{b}}, v_{\mathrm{c}}, i_{\mathrm{a}}, i_{\mathrm{b}}, i_{\mathrm{c}}$ are rotor winding voltages and currents, $R_{\mathrm{A}}, R_{\mathrm{B}}, R_{\mathrm{C}}$ are stator winding resistances, $L_{\mathrm{s}}$ is stator winding self inductance, $R_{\mathrm{a}}$, $R_{\mathrm{b}}, R_{\mathrm{c}}$ are rotor winding resistances, $L_{\mathrm{r}}$ is rotor winding self inductance, $M_{\mathrm{s}}$ is the mutual inductance between pairs of stator windings, $M_{\mathrm{r}}$ is the mutual inductance between pairs of rotor windings, $M$ is the peak value of rotor position dependent mutual inductance between stator/rotor winding pairs, $\theta_{1}$ is the rotor position angle measured in electrical radians, $\theta_{2}=\theta_{1}+2 \pi / 3$ and $\theta_{3}=\theta_{1}+4 \pi / 3$.

Only the stator and rotor winding resistances are separately defined, and subsequently adjusted during the search routine. Of course many faults also have an impact on machine inductance parameters and to obtain an exact match between measured and modeled armature currents (Fig. 1) under fault conditions it would be necessary to include the inductance parameters in the search. However, the aim of this work is not to completely identify the faulted machine parameters, but rather to demonstrate the new technique by using it to identify the location and type of rotor and stator series winding faults. Other machine faults could of course be included by extending the search to take in a wider range of machine parameters.

Because the six winding resistances may have different values, there is no advantage in seeking to transform the machine equations into an alternative reference frame. Instead the six winding voltage equations in are simply subjected to the constraints imposed by winding connection (star or delta) and short-circuiting of the secondary, then solved by numerical integration.

\section{EXPERIMENTAL RESULTS}

A three-phase, $50 \mathrm{~Hz}, 240 \mathrm{~V}$, 2-pole wound-rotor induction motor rated at $1.5 \mathrm{~kW}$ was used to obtain experimental results for both healthy and faulted operating conditions. Both the stator and rotor windings of the machine are delta connected, though the rotor delta is short-circuited between all three terminals, giving effectively three independent short-circuited windings. Standard tests (dc resistance, no-load and locked rotor tests) were carried out to determine the nominal values of the machine parameters, giving the following results:

$$
R_{\mathrm{A}}=R_{\mathrm{B}}=R_{\mathrm{C}}=3.47 \Omega, R_{\mathrm{a}}=R_{\mathrm{b}}=R_{\mathrm{c}}=4.3 \Omega, L_{\mathrm{s}}=0.29 \mathrm{H},
$$$$
L_{\mathrm{r}}=0.47 \mathrm{H}, M_{\mathrm{s}}=0.14 \mathrm{H}, M_{\mathrm{r}}=0.23 \mathrm{H} \text { and } M=0.36 \mathrm{H} \text {. }
$$

$\left[\begin{array}{c}v_{A} \\ v_{B} \\ v_{C} \\ v_{a} \\ v_{b} \\ v_{c}\end{array}\right]=\left[\begin{array}{cccccc}R_{A}+L_{s} p & M_{s} p & M_{s} p & M p \cos \theta_{1} & M p \cos \theta_{2} & M p \cos \theta_{3} \\ M_{s} p & R_{B} & M_{s} p & M p \cos \theta_{3} & M p \cos \theta_{1} & M p \cos \theta_{2} \\ M_{s} p & M_{s} p & R_{C} & M p \cos \theta_{2} & M p \cos \theta_{3} & M p \cos \theta_{1} \\ M p \cos \theta_{1} & M p \cos \theta_{3} & M p \cos \theta_{2} & R_{a}+L_{r} p & M_{r} p & M_{r} p \\ M p \cos \theta_{2} & M p \cos \theta_{1} & M p \cos \theta_{3} & M_{r} p & R_{b}+L_{r} p & M_{r} p \\ M p \cos \theta_{3} & M p \cos \theta_{2} & M p \cos \theta_{1} & M_{r} p & M_{r} p & R_{c}+L_{r} p\end{array}\right]\left[\begin{array}{c}i_{A} \\ i_{B} \\ i_{C} \\ i_{a} \\ i_{b} \\ i_{c}\end{array}\right]$


For each of the operating conditions discussed below, data was collected over a time window of $0.4 \mathrm{sec}$, with a sampling interval of $1 \mathrm{~ms}$, as the machine accelerated from rest following the direct switch on of the 3-phase supply voltage. The acquired data was then processed off-line using the particle swarm algorithm to determine the effective resistances of the six windings.

\section{A. Initial Test using Healthy Machine}

Initially, a test was carried out with the healthy, un-faulted machine to ensure that no spurious fault indications would arise and also to illustrate the behavior of the particle swarm algorithm. The three graphs in Figs. 2-4 show the two sets of estimated winding resistances and the error produced by the existing solution. About 25 investigations of potential solutions were required to obtain convergence of the two sets of estimated resistances to common values. The calculation error falls from a maximum value of 28 A.s, before gradually reducing to 5.5 A.s. These values of calculation error must be considered in the context of peak currents in the three stator windings reaching $60 \mathrm{~A}$ throughout the $0.4 \mathrm{~s}$ data window. The simplicity of the motor model means that it would be unreasonable to expect the calculation error to reduce to zero, even with a larger number of investigations.

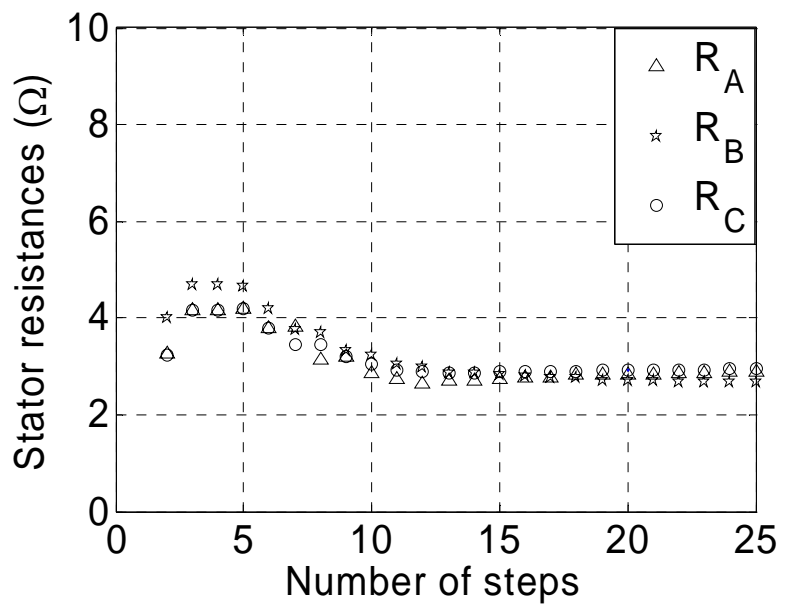

Fig. 2. Stator resistance estimation for healthy operating conditions.

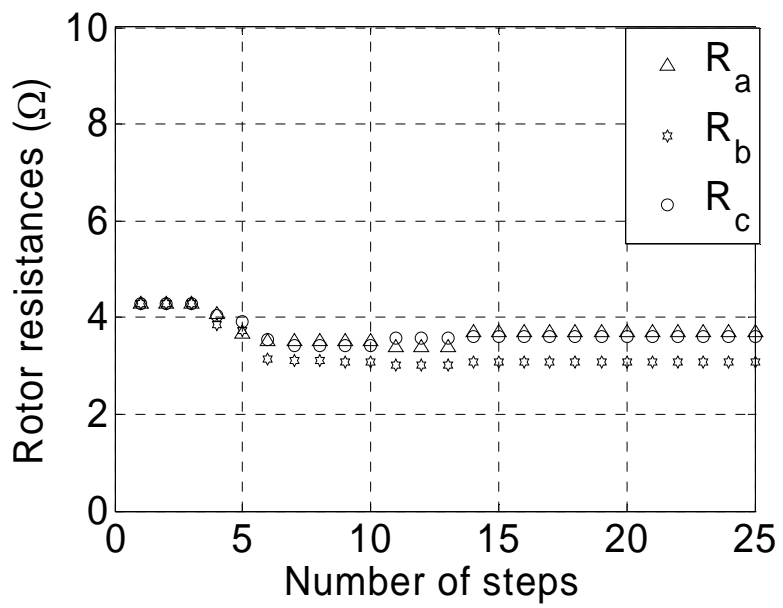

Fig. 3. Rotor resistance estimation for healthy operating conditions.

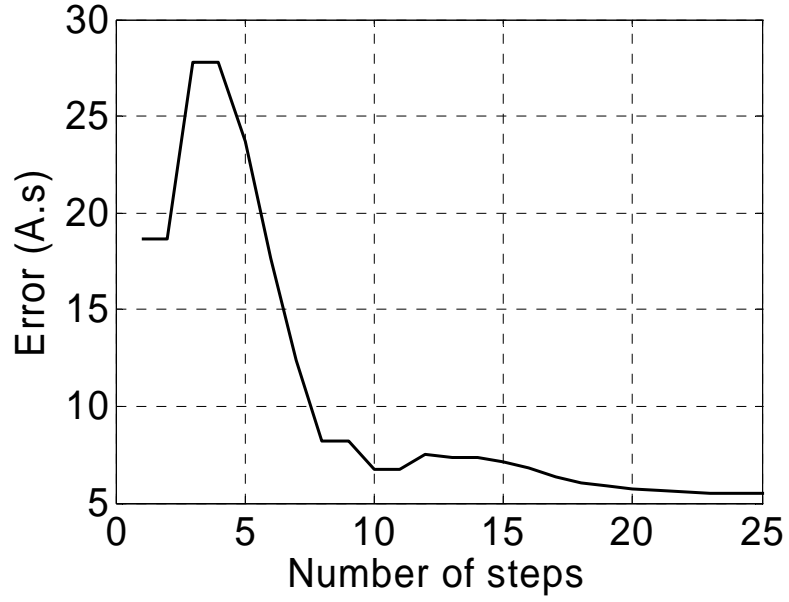

Fig. 4. Current estimation error for healthy operating conditions.

\section{B. Search for Rotor Winding Series Fault}

A $5 \Omega$ resistance was then placed in series with rotor winding $a$ to mimic a developing rotor winding open-circuit fault. The operation of the particle swarm algorithm as it estimates the winding resistances is illustrated in Figs. 5-7. A clear trend is established very quickly, with the estimated resistance of rotor winding $a$ being noticeably higher than that of the other two rotor resistances. These trends become firmly established over the subsequent 25 investigations and highlight the presence of a developing open-circuit fault in rotor winding $a$. The calculation error in this case falls from a maximum value of 16 A.s, before gradually reducing to just less than 6.8 A.s.

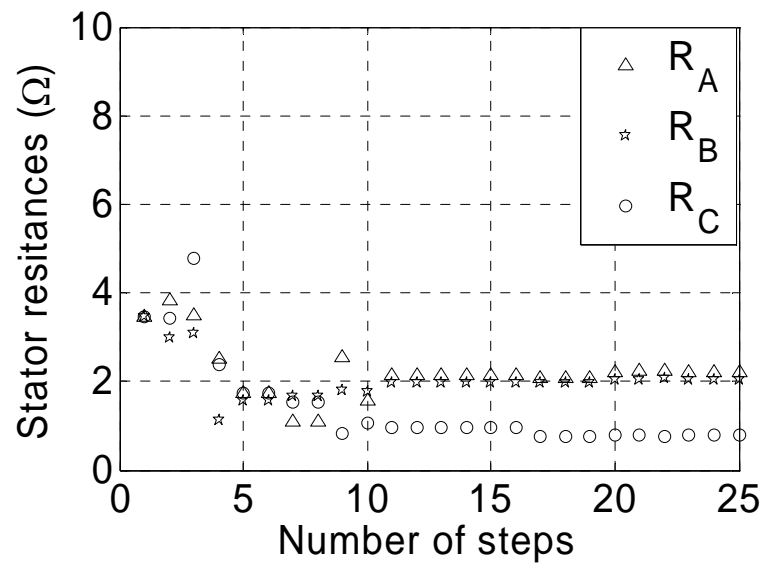

Fig. 5. Stator resistance estimation for operation with rotor winding fault 


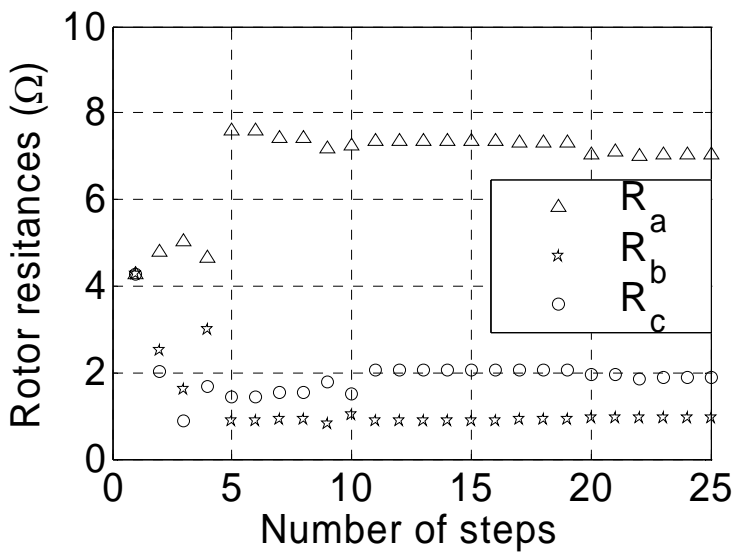

Fig. 6. Rotor resistance estimation for operation with rotor winding fault

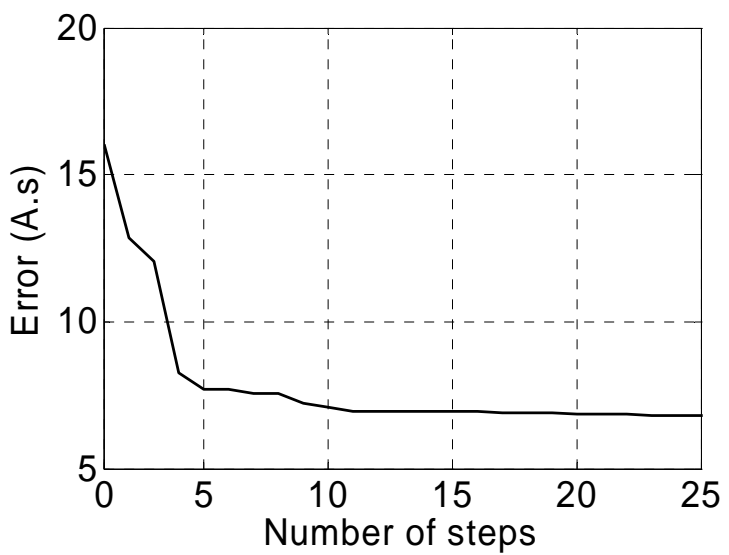

Fig. 7. Current estimation error for operation with rotor winding fault

\section{CONCLUSIONS}

A new condition monitoring technique based on particle swarm optimization is shown to be able to identify the type and location of a motor winding series fault. Because the technique uses time-domain data, there is no requirement for the machine to be in a steady-state operating condition: in fact data acquired during a starting transient may be more helpful in discriminating between healthy and fault conditions.

The general scheme, described here for a wound rotor induction motor, is capable of being further developed by including in the machine model an appropriate set of equations to describe the secondary circuits of a cage induction machine. Other machine faults, such as inter-phase and inter-bar faults, could be included by extending the search to cover a wider range of machine parameters, including the inductances of the machine

\section{REFERENCES}

[1] P. J. Tavner, and J. Penman, Condition monitoring of electrical machines, Research Studies Press, 1987, Letchworth, England, (1987).

[2] M. E. H. Benbouzid. "A review of induction motors signature analysis as a medium for faults detection", IEEE Transactions on Industrial Electronics, vol. 47, pp. 984-992, 2000.

[3] A. J. Trzynadlowski, and E. Ritchie. "Comparative investigation of diagnostic media for induction motors: a case of rotor cage faults", IEEE Transactions on Industrial Electronics, vol. 47, pp. 1092-1099, 2000.
[4] F. C. Trutt, J. Sottile, and J. L. Kohler. "Online condition monitoring of induction motors”, IEEE Transactions on Industry Applications, vol. 38, pp. 1627-1632, 2002.

[5] H. Douglas, P. Pillay, A. K. Ziarani. "Broken rotor bar detection in induction machines with transient operating speeds”, IEEE Transactions on Energy Conversion, vol. 20, pp. 135-141, 2005.

[6] M. S. N. Said, M. E. H. Benbouzid, and A. Benchaib. "Detection of broken bars in induction motors using an extended Kalman filter for rotor resistance sensorless estimation”, IEEE Transactions on Energy Conversion, vol. 15, pp. 66-70, 2000.

[7] J. Kennedy, and R. C. Eberhart, "Particle Swarm Optimization”, in Proc. 1995 IEEE International Conference on Neural Networks, pp. 19421948.

[8] C. Picardi, and N. Rogano, "Parameter Identification of Induction Motor Based on Particle Swarm Optimization", in Proc. 2006 International Symposium on Power Electronics, Electrical Drives, Automation and Motion, pp. 32-37.

\section{BIOGRAPHIES}

Salah Ethni was born in Tripoli in Libya on December 18, 1971. He received his BSc in Electrical and Electronic Engineering from the Bright Star University of Technology, Libya, in 1994 and his MSc from the Newcastle University, UK, in 2004. He is currently conducting his $\mathrm{PhD}$ studies at Newcastle University, UK.

Paul Acarnley received the BSc and PhD degrees in Electrical Engineering from Leeds University, UK, in 1974 and 1977, respectively, and an MA degree from Cambridge University, UK in 1978. After seven years in the Department of Engineering at Cambridge University, he joined the Power Electronics, Drives and Machines Group at Newcastle University, UK, in 1986. He authored 'Stepping Motors: a guide to theory and practice' which was first published by the IEE in 1982 with the 4th edition appearing in 2002. In 2003 Paul Acarnley founded RESEEDS (Research Engineering Education Services) based in Stonehaven, Scotland. He is also a Research Professor in the School of Engineering at Robert Gordon University, Aberdeen, UK and Emeritus Professor and Research Advisor at Newcastle University, UK. His principal research interest is in the control of electric drives, including work on state and parameter estimation applied to torque, current, temperature, speed and position estimation in motors, and temperature estimation in power electronic devices.

Bashar Zahawi received his BSc and $\mathrm{PhD}$ degrees in electrical and electronic engineering from the University of Newcastle, England, in 1983 and 1988, respectively. From 1988 to 1993 he was a design engineer at Cortina Electric Company Ltd, a UK manufacturer of large ac variable speed drives and other power conversion equipment. In 1994, he was appointed as a Lecturer in Electrical Engineering at the University of Manchester and in 2003 he joined the School of Electrical, Electronic \& Computer Engineering at Newcastle University, where he is currently the Director of Postgraduate Studies. His research interests include power conversion, variable speed drives and the application of nonlinear dynamical methods to transformer and power electronic circuits.

Damian Giaouris received the diploma of Automation Engineering from the Automation Department, Technological Educational Institute of Thessaloniki, Greece, in 2000, the MSc degree in Automation and Control with distinction from Newcastle University in 2001 and the $\mathrm{PhD}$ degree in the area of control and stability of Induction Machine drives in 2004. His research interests include advanced nonlinear control \& estimation of electromagnetic devices, and nonlinear phenomena in power electronic converters. He is currently a lecturer in Control Systems at Newcastle University, UK. 